Vol. 4, Special Issue 2, January 2017

\title{
Energy Efficient Outdoor Light Monitoring and Control Architecture using Embedded System
}

\author{
Mr. Nalawade Pritam ${ }^{1}$, Prof. Prakash Chorage ${ }^{2}$ \\ Student -Bachelor of Engineering, Electronics \& Telecommunication Engineering Department, Dr. Daulatrao Aher \\ College of Engineering, Karad, Maharashtra, India ${ }^{1}$ \\ Associate Professor, Electronics \& Telecommunication Engineering, Dr. Daulatrao Aher College of Engineering, \\ Karad, Maharashtra, India ${ }^{2}$
}

\begin{abstract}
In this project, we proposed an energy efficient outdoor light monitoring and control system that can monitor and handle outdoor lights more efficiently as compared to the conventional systems. The proposed system uses the GSM wireless devices which allow more efficient lamps management. The Energy Consumption of outdoor or a specific area can be recorded and account on Energy Saving Lighting System with integrated sensors and controllers. Moreover, errors which occur due to manual operation can also be eliminated. Also the outdoor lights can be switch ON/OFF through computer from central control station or can be automatic using light sensors embedded in the outdoor light pole circuit of the application. With these facilities the performance and life of the lamps will be increases.
\end{abstract}

Keywords: GSM wireless devices, sensors, controllers.

\section{INTRODUCTION}

In the present system, mostly highways are used High of maintenance and energy savings and it is appropriate Intensity Discharge lamps (HID) for lighting, whose for outdoor lighting in remote as well as urban areas. The energy consumption is very high. Its intensity cannot be system is all round, expandable and totally adjustable to controlled. so there is a need to switch on/off or to an user needs. alternative method of lighting system i.e., by using LEDs. This system is built to overcome the drawbacks of HID lamps.

A. Block diagram:

White Light Emitting Diode (LED) replaces HID lamps in The following fig. 1 . Shows the schematic block diagram outdoor lighting system for dimming purpose. The microcontroller 89C51 is main component of whole microcontroller 805 lis used to control the light intensity. circuit.

This system uses LEDs (light emitting diodes) as the light source and it have variable intensity control as per requirement. the LED consumes less power and its life is more, as compared to the other conventional lamps. The most important feature is intensity can be controlled as per requirement for long time which is not available in HID lamps. A group of LEDs are used in the form a

outdoor light. The microcontroller have programmable instructions which controls the intensity of lights. [1]

The intensity of lights are kept high during few hours because of high traffic. when the traffic on the roads goes decrease slowly in the late nights, then intensity of light decreases in steps till morning. At the morning time, it is completely shuts down. At evening, the system goes resume and the process will be start repeated.

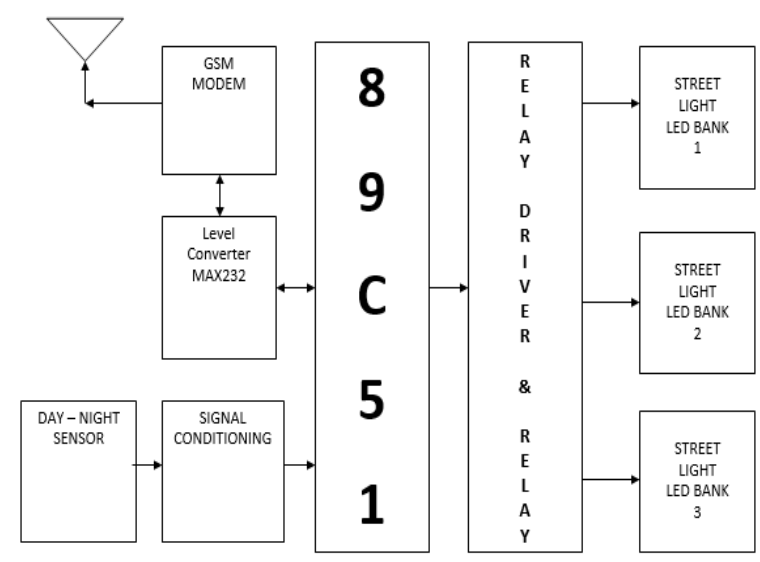

\section{PROPOSED SYSTEM}

Proposed system overcomesdrawbacksof existing systemby using GSM technology. In our project, the proposed system integrates new technologies offering ease

\section{POWER SUPPLY \\ $+12 \mathrm{Vdc}$ and $+5 \mathrm{Vdc}$}

Fig.1. Basic block diagram 


\section{B. Working:}

The LDR sensor and Relay are connected to the iii. Relay Driver:-

microcontroller 89C51. The power supply also provide to Output of micro-controller is not sufficient to drive the the microcontroller. The GSM module is also connected to relay directly. Therefore to drive the relay we are using microcontroller for transmit the data and control the light. relay driver i.e. transistor as switch. We are using The LDR sensor detects the intensity of light and transmit transistor IC ULN2804. This IC has 8 transistor in it.

the information to the microcontroller. Microcontroller collect information and take the decision ON/OFF of the light. The Relay are used for the dimming the light after sometime. The GSM module is used for transmit the information to the server computer or user for monitor or control the light.

It can be operate automatic or manual. In automatic mode, microcontroller take the decision itself to operate the light and information send to the server computer for only monitor the light. In manual mode, microcontroller do not take decision itself.Microcontroller collect the information from the sensor and send to the server computer or user. Server computer or user take decision to operate the light and control it.

\section{HARDWARE DESIGN}

i Power supply:-

For our project we require a $+5 \mathrm{v}$ power supply. This power supply can be designed using voltage regulator IC 7805 .

\section{ii Micro-controller 89C51:-}

The IC 89C51 is a low-power, high-performance CMOS 8-bit microcomputer. It have $4 \mathrm{~K}$ bytes of Flash Programmable and Erasable Read Only Memory (PEROM). The device is produced by using Atmel's highdensity non-volatile memory technology and it is corresponding with MCS-51 ${ }^{\mathrm{TM}}$ instruction set and pin-out. The on-chip Flash memory which allows the program memory to be reprogrammed in-system or by a conventional non-volatile memory programmer. By combining an all-round 8-bit CPU with Flash memory on a monolithic chip, the Atmel AT89C51 become a powerful microcomputer, which provides a highly flexible and cost effective solution in so many embedded control applications.

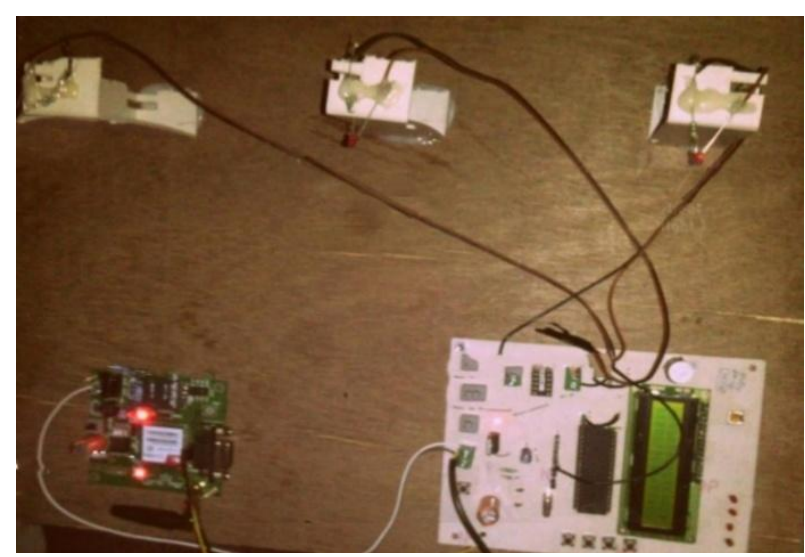

Fig.2. proposed system iv. Relay:-

Relay is electromechanical switch. This electromechanical switch is used to turn ON-OFF the LED lamp. In DAY condition relay is OFF, NO remains $\mathrm{NO}$ and LED lamp is OFF.In NIGHT condition relay is $\mathrm{ON}$, NO becomes NC and power is connected to LED Lamp.

We are using relay for intensity control that is dimming purpose also.[6] We are using two resistors for changing the current. By changing resistor value we can change the intensity of LED lamp.

\section{v. GSM MODEM:-}

GSM modem is a wireless modem which works with a GSM wireless network. A wireless modem transmits and receives data through radio waves. The data like a GSM mobile phone, a GSM modem requires a SIM card from a wireless carrier in order to operate.[2]

\section{vi. GSM Interfaces}

- it interface RS-232 through D-TYPE 9 pin connector, the Serial port baud rate adjustable 1200 to115200 bps (9600 default)

- Power supply through DC socket

- SMA antenna connector

- SIM holder like push switch

- LED status of GSM / GPRS module

For sending SMS in text Mode:

$\mathrm{AT}+\mathrm{CMGF}=1$ press enter

$\mathrm{AT}+\mathrm{CMGS}=$ press enter "mobile number"

Once The AT commands is given ' $>$ ' prompt will be displayed on the screen. The message transfer through the SMS. After this, press ctrl $+Z$ to send the SMS. Supposethe SMS transferring is successful, then "ok" will be displayed on the message number. [5]

\section{vii. DAY \& NIGHT Sensor:-}

This is one of the main part of our project. The main intention of this block is to sense the DAY or NIGHT. For checking light intensity, we are using the light dependent register (LDR). [3] In nebulous condition i.e. night, the resistance of LDR is very low. And in glow condition i.e. DAY, the resistance of LDR is very high.

\section{SOFTWARE DESIGN}

The Keil C51 is the most popular $8051 \mathrm{C}$ compiler in the world. It provides more features as compared to other $\mathrm{C}$ compiler. The C51 Compiler allows you to write 8051 microcontroller applications in $\mathrm{C}$ which have the efficiency and speed of assembly language. [7]In the C51 
Compiler, it give youfull access to all resources of the 8051.

\section{CONCLUSION}

Thus the proposed system absolute new technologies offering ease of maintenance and energy savings and it is appropriate for outdoor lighting in remote as well as urban areas. The system is all round, expandable and totally adjustable to user needs.

\section{FUTURE SCOPE}

Once this Intelligent System is implemented, we can go for Wireless Power Transmission. That will be reduce the maintenance costs and power of the system, as cable breaking is one of the problems faced nowadays. Moreover, the attempts can be complete system is selfsufficient on nonconventional energy resources like solar power, windmills, Piezo-electric crystals, etc. We hope that these advancements can make this system completely strong and totally sure in all viewpoints.

\section{REFERENCES}

[1] ZeeshanKaleem, "Energy Efficient Outdoor Light Monitoring and Control Architecture Using Embedded System", Article in IEEE embedded systems letters October 2015.

[2] Lakshmiprasad,Keerthana "Smart Street Lights", International Journal of Students Research in Technology \&Management Vol 2 (02), 2014

[3] Resmi Karun, MinuJohny, P.G. Scholar, "Street Light Commander System Using Zigbee Network of Devices"International Journal of Engineering and Innovative Technology (IJEIT) Vol. 4, Issue 4, 2014

[4] Srikanth M, Sudhakar K N, "ZigBee Based Remote Control Automatic Street Light System”, IJESC ISSN-2321 -3361, 2014.

[5] Prof. K.Y.Rajput, Priyanka Yadav, "Intelligent Street Lighting System Using GSM", International Journal of Engineering Science Invention March 2013.

[6] A.Siddiqui, A. W. Ahmad, H.K.Yang and C.Lee, "Zigbee based energy efficient outdoor lighting control system" in Proc. ICACT, vol 4, Issue 5, 2012.

[7] Fabio Leccese. "Remote-Control System of High Efficiency and Intelligent Street Lighting Using a ZigBee Network of Devicesand Sensors'IEEE Transaction Power Delivery, Vol.28, No.1, JAN 2012. 